Original article

\title{
Comparative characteristics of the xenogenic synthetic biomimetic composite and spongy bone tissue for the goals of osteoplasty in dentistry
}

\author{
Pavel V. Seredin ${ }^{1}$, Dmitry L. Goloshchapov ${ }^{1}$, Maksim S. Gushchin ${ }^{1}$, Yuri A. Ippolitov ${ }^{2}$, Vladimir M. Kashkarov ${ }^{1}$, \\ Dmitry E. Suetenkov ${ }^{3}$
}

\author{
${ }^{1}$ Voronezh State University, Voronezh, Russia \\ ${ }^{2}$ Voronezh State Medical University, Voronezh, Russia \\ ${ }^{3}$ Saratov State Medical University, Saratov, Russia
}

Received 09 August 2018, Revised 6 Desember 2018, Accepted 28 February 2019

(C) 2018, Seredin P.V., Goloshchapov D.L., Gushchin M.S., Ippolitov Y.A., Kashkarov V.M., Suetenkov D.E.

(C) 2018, Russian Open Medical Journal

Abstract: Background - The structural and morphological features in the natural and synthetic biomimetic composites should be defined and compared to determine the optimal artificial material for osteoplastic tasks.

Methods - The sample of osteoplastic material of the xenogenic group representing the treated bone blocks of cattle, sample of a spongy bone tissue of a human lower jaw and a sample of biomimetic carbonate-substituted calcium hydroxyapatite synthesized with the use of birds' egg-shells were studied using X-ray diffraction (XRD) and Fourier Transmission Infrared spectroscopy (FTIR) for the structure, phase and molecular composition analysis, X-ray spectral microanalysis (XMA) was applied for chemical element composition, optical and scanning electron microscopy (SEM) were used for a surface features analysis of the materials with a porous structure.

Results - The analysis of the xenogenic material as well as the bone tissue sample by XRD and FTIR reveal that the samples are comprised of a single crystalline phase, i.e. a carbonate-substituted calcium hydroxyapatite (CHAP) with distortions in the crystalline structure. The calculations of the hydroxyapatite crystallites size in the samples of the bone tissue and the xenogenic materials by the XRD data are $35.2 \pm 1.5 \mathrm{~nm}$ and $11.1 \pm 0.6 \mathrm{~nm}$ respectively. A different content of the amide and carboxyl groups in the bone tissue and in the osteoplastic material were found using IR-spectroscopy in the 1,800-1,200 $\mathrm{cm}^{-1}$ indicates the presence of protein structures in the latter which are different in the molecular structure from those presented in the native human bone tissue. The redistribution of the vibration modes in the spectral ranges $3000-2800$ and $800-500 \mathrm{~cm}^{-1}$ also confirm this suggestion. Scanning electron microscopy demonstrated that xenogenic materials possess the morphology and a system of conjugated pores similar to those of the human bone tissue. At the micrometer level the pores that are present in the xenograft coincide in their size with those in the native bone matrix (3-6 $\mu \mathrm{m})$. Optical microscopy investigations shows that in the osteoplastic xenogenic materials at the macrolevel there are no pores with the size of $0.25-1.5 \mathrm{~mm}$, which are observed in the samples of the native bone tissue.

Conclusion - Based on the results of comparison of the structural, molecular and morphological properties of the studied samples, it is possible to conclude that the samples of the osteoplastic materials do not completely correspond to the spongy human bone tissue, which imposes certain constraints on their practical applications. Comparison of the structure, phase and molecular composition as well as the morphology of the samples of native porous bone tissue and xenogenic materials allowed us to identify the principal differences between the two materials as well as to design the requirements and guidelines for manufacturers on extra processing of a xenogenic material for eliminating the factors affecting the quality of implantation and resorption of a biomimetic composite: macroporosity, crystallinity and molecular composition.

Keywords: dental hard tissues, biomimetic materials, osteoplastic, xenogenic materials, carbonate-substituted calcium hydroxyapatite.

Cite as Seredin PV, Goloshchapov DL, Gushchin MS, Ippolitov YA, Kashkarov VM, Suetenkov DE. Comparative characteristics of the xenogenic synthetic biomimetic composite and spongy bone tissue for the goals of osteoplasty in dentistry. Russian Open Medical Journal $2019 ; 8$ : e0206.

Correspondence to Pavel V. Seredin. Address: Department of Solid State Physics and Nanostructures, Voronezh State University, 1 University sq., Voronezh, 394006, Russia. E-mail: paul@phys.vsu.ru. Phone: +74732208363.

\section{Introduction}

At present synthetic organic-mineral materials with qualitatively different properties are elaborated, investigated, and applied in order to replace various defects of the hard dental tissues [1-4]. The nature of these materials can be either purely synthetic: materials are obtained as a product of chemical relations or biogenic ones where samples represent a kind of the treatment of a biological object $[5,6]$. Both of the approaches are aimed at designing dental materials including those for oral surgery with the structure, composition and morphology that are closest to hard human tissues. This is one of the most rapidly developing trends in the contemporary biomaterial sciences $[1,2,4]$. 
It was proved that the best results in the integration with the bone tissue just demonstrated those materials that are comprised of the analogue of the mineral compound in the bone human tissue - calcium hydroxyapatite (HAP) and organic matrix used for the improvement of the reparative processes, increase in the resorption rate and strength [1, 3, 7-9]. Complex materials biocomposites, elaborated on the basis of calcium hydroxyapatite, collagen, chitosan or any other biodegradable organic matrix have a lot of advantages for dental applications implying the control of their bioactivity and resorption rate $[2,8,10]$. At the same time the presence of the characteristics inherent to the animals that are similar to the human bone: hierarchical structure, morphology, mechanical strength as well as their commercial availability results in the elaboration of new ways of treatment and modification of these xenografts for oral surgery [11-13].

The generally accepted trend for reducing the risks of rejection of the xenogenic samples involves the incorporation of the medical preparations or some organic agents $[7,9,13]$. However, the rate of biodegradation and osseointegration of synthetic samples can be determined based on their surface characteristics as well as performed preliminary treatment including the side action effect of introduced agents.

It should be noted that ideal implantable objects comprised of metal or ceramics for oral surgery tasks should be porous composite materials close in phase composition and morphological characteristics to those of biogenic samples $[1,4$, 11]. Morphological organization of synthetic samples has limited the ability of the practical applications for these synthetic biocomposites, namely, the porosity of a material, hierarchy (agglomeration and mutual pores conjugation, their size distribution), bulk share of pores and a specific surface area [2, 4]. At the same time, it is well-known that the predefined surface and bulk properties of a material will provide bone tissue cells inside an implantable object in case of tooth prosthetics $[4,14]$.

The materials for oral surgery prosthetic currently proposed and applied in oral surgery prosthetics are different in their composition and the level of structural organization $[1,2,14]$. A separate issue for the complex systems (e.g., xenographs) that presents a certain interest for researchers is a set of refinement techniques from the protein components and their application for a certain application. Although these materials are to the best extent suitable for replacement of a lost part of the human bone, there is a high probability of rejection of an osteoplastic material due to an individual reaction of an organism [15]. Both advantages and drawbacks found in synthetic materials for osteoplastics in oral surgery stipulate are a prerequisite for search of new ways in their preparation and comparison of their parameters with the native human bone tissue.

Thus, the aim of this work is to compare the structural and morphological features in the natural and synthetic biocomposites in order to define the optimal material for osteoplastic tasks.

\section{Materials and Methods}

The work was performed at the base of the joint research laboratory "Dental functional bioactive nanomaterials" (Voronezh State University, Central Research Institute of Dental and Maxillofacial Surgery, and Voronezh State Medical University).

\section{Materials}

The following materials were chosen for the investigations and comparison of their properties. Sample 1 - osteoplastic material of xenogenic group representing the treated bone blocks of the cattle. This material is composed of an organic component related to collagen of the 1-st type as well as of sulfated glycosaminoglycans (GAG) introduced for the acceleration of the reparative processes [16]. Sample 2 is a spongy bone tissue of the human lower jaw; its composition is described in detail in a number of works (for example [11, 12]). Sample 3 is biomimetic carbonate-substituted calcium hydroxyapatite synthesized with the use of birds' egg-shells according to the technique in [17]. According to today's representations, all of the samples are related to calcium phosphates, namely, to calcium hydroxyapatite with different morphological organization. In total, 5 parts of the samples of the same kind obtained at different time were investigated. The experimental data provided in the work for each type of the samples were averaged over the group in order to exclude accidental errors appearing in the experiments.

\section{Methods}

The structure and determination of the phase composition of the inorganic component for the samples $1,2,3$ described above was studied by means of $X$-ray diffraction with the use of Thermo ARL $X$ 'TRA diffractometer with monochromated copper radiation with a wavelength of CuK $1=1.5405 \AA$. As it was repeatedly shown before, this method provides an integral estimation of the atomic structure in the inorganic and biogenic materials and helps to reveal its inhomogeneities, defects and distortions in biological samples [18, 10]. It also allows the determination of nanocrystals in the biological objects and the presence of impurity phases and as a result, identification of the fundamental properties of various materials. $X$ ray phase analysis (XRD analysis) was performed with the use of the International Center for Diffraction Data (ICDD). The experimental XRD data were averaged for each sample through the obtained diffractograms from 5 parts of each sample and the averaged results were compared in order to obtain precise information for structural differences between the materials. All operations for phase analysis were provided in program complex Match! version 3.5.2.104.

The study of the molecular composition including the organic component of biogenic materials was performed based on the infrared Fourier spectroscopy. As for the application of this technique with respect to dentistry, the advantage of this method is its high selectivity and sensitivity [18-20]. It allows one to get the information on the structure of a substance, to find newly formed mineral phases as well as the distortions introduced by a new molecular interaction [3, 12]. One more advantage of IRspectroscopy is its ability to analyze multicomponent compounds $[21,22]$. Unlike a number of the methods of analysis when using this technique, the studied system is subjected to weak external exposures. It means that the obtained information is related to the system that was not changed as a result of these exposures. The IR spectra were registered with the VERTEX-70 spectrometer with standard room temperature DLaTGS detector and an attached attenuated total reflection (ATR) diamond PLATINUM ATR equipment in the range of $4000-500 \mathrm{~cm}^{-1}$ produced by "Bruker" Company. The background spectra were registrated before each sample investigation refers to air. Spectral data processing (background subtraction, correction for the atmosphere effect, averaging of the spectra and data integration) and analysis were performed using the professional software suite OPUS (version 7.5). 


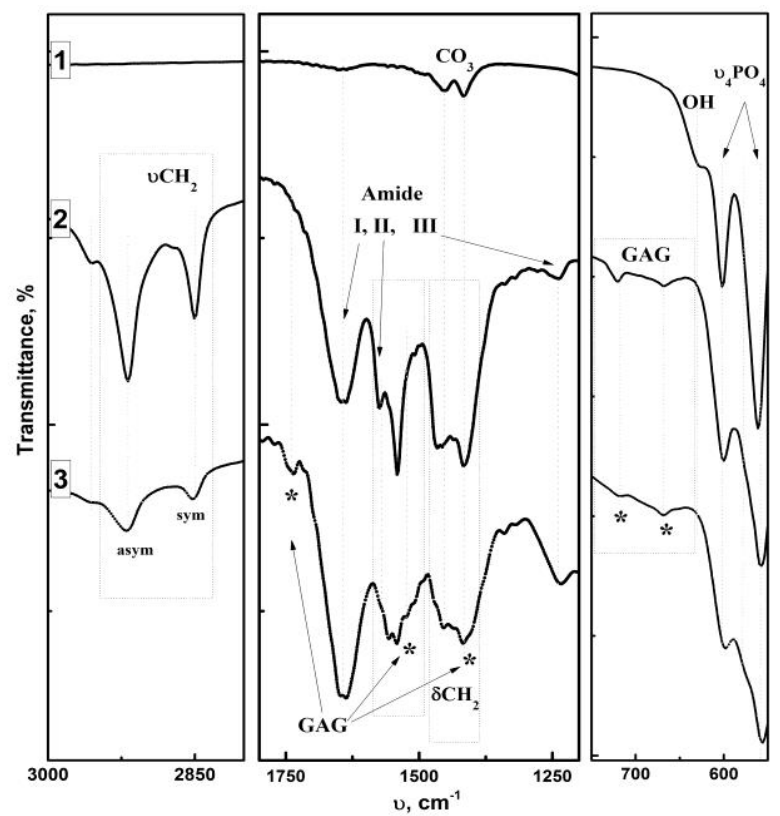

Figure 1. Separated areas of the changes in the IR-spectra of the investigated materials. 1 - synthesized hydroxyapatite sample, 2 - bone tissue, 3 - xenogenic material, ${ }^{*}$ - modes, related to glycosaminoglycan (GAG).

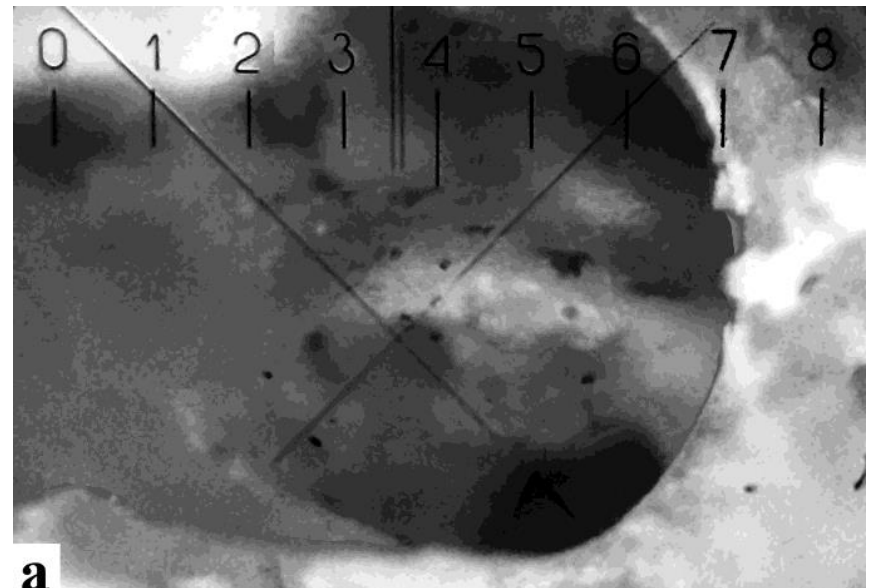

a



Figure 2. Images obtained with the use of optical microscope for morphology of the bone tissue samples (left) and osteoplastic xenogenic materials (right) under x120 magnification.
The chemical element composition for the obtained materials was determined by means of X-ray spectral microanalysis (XMA) with X-ray microanalyzer JED-2200, i.e. an attachment to the scanning electron microscope JSM-6380LV where at high level of magnification morphology of the investigated samples was studied as well. The surface features at low level of magnification of the materials with a porous structure were investigated by means of optical microscopy with the use of an optical microscopy supplied durometer PMT-3.

All of the studies were performed with the involvement of the equipment base at Voronezh State University.

\section{Statistical analysis}

Statistical analysis of experimental data for each type of the samples was performed with the use of the professional software for the statistical analysis SPSS v. 19 for Windows, (SPSS Inc., Chicago, Illinois, USA). The results of XRD and microscopy analysis are presented as a mean value \pm standard deviation or the range of possible values.

\section{Results}

Investigations of materials by $\mathrm{X}$-ray diffraction in order to refine the phase composition and structure of inorganic component of the samples demonstrated that the xenogenic material (sample 1), the spongy bone of a human lower jaw (sample 2) and the calcium-phosphate material synthesized in accordance to our elaborated technique [17] (sample 3) were characterized by the structure of calcium hydroxyapatite with the different crystal structure features. The analysis of the samples showed that the bone tissue of human and bone-induced blocks obtained from a thigh bone of cattle (samples 1 and 2) involved distortions in the crystalline structure as a result of defects. Moreover, the comparison of the intensities of same diffraction peaks in width and intensity of the xenograft, bone and synthetic hydroxyapatite shows significant differences that are refer to the crystal growth, size and texture.

The results of the investigations for synthetic and natural materials by means of X-ray microanalysis technique confirmed that all of the materials studied in the work were calcium phosphates with the different ratio of $\mathrm{Ca} / \mathrm{P}$ that is upper then to stoichiometric one: 1.67 . The $\mathrm{X}$-ray spectral microanalysis allow to define that for synthetic hydroxyapatite material this value is 1.83 , that are refer to the synthesis [17]. For xenograft sample the value of $\mathrm{Ca} / \mathrm{P}$ ratio is 2.1 and for native bone sample more then 2.6 what is due to the high amount of trace elements in biological sample [23]. The high content of carbon in these samples is bound with the presence in xenograft organic adding's and in bone of protein matrix.

The Fourier Transmission Infrared spectroscopy (FTIR) analysis show that the mineral part of the samples are comprised of a single crystalline phase, i.e. a carbonate-substituted calcium hydroxyapatite (CHAP) and confirmed the XRD data [3, 24]. In order to study the features in the molecular composition and to detect the differences in the organic matrix of the studied samples the IR-spectra was thoroughly investigated in the following regions $3000-2800 \mathrm{~cm}^{-1}, 1800-1200 \mathrm{~cm}^{-1}$ and $800-500 \mathrm{~cm}^{-1}$ (Figure 1). The changes of relative intensities of vibration modes: 2956, 2919, 2850, 1452, $1416 \mathrm{~cm}^{-1}$ of $\mathrm{CH}_{2}$ vibration group, Amide I, II, III vibration bands at $1645,1574,1240 \mathrm{~cm}^{-1}$, groups of 
glycosaminoglycans (GAG) at 1740, 1521, 720, $668 \mathrm{~cm}^{-1}$, introduced in xenograft material and hydroxyapatite modes 629 , 601 and $560 \mathrm{~cm}^{-1}$ shows the presence in xenograft materials as high amount of GAG, as an organic matrix of xenograft materials that is differ to those in the sample of spongy bone tissue of the human lower jaw.

Due to the different hierarchical organization of the studied materials as well as for the purpose of detecting of the residual organic fibers in biocomposites, the study of the morphology for the samples of the groups 1, 2, 3 was performed by means of optical microscopy and scanning electron microscopy (SEM). The results of the optical microscopy (Figure 2) demonstrated that osteoplastic material differs from the spongy bone tissue in its morphological structure not only by its hierarchical structure but also by the pore sizes of the osteal matrix. However, in the osteoplastic xenogenic materials at the macrolevel there are no pores with the size of $0.25-1.50 \mathrm{~mm}$, which are observed in the samples of the native bone tissue (Figure 2 ).

The microphotographs of the samples obtained by SEM are presented in Figure 3. It is seen that under a high magnification the bone tissue samples (Figure 3a) and xenogenic material (Figure 3b) show a rather similar morphology. The size of the observed pores is of 3-10 $\mu \mathrm{m}$, thus indicating a similar microporosity of the used material on the basis of the spongy bone tissue of a cattle and human spongy bone tissue.

\section{Discussion}

According to the known XRD data, the composition of the biological materials involves a great number of foreign ions and complexes that just prove to be the cause of distortions in the structure of the biogenic HAP with different morphological organization [25]. In this work comparison of the diffraction data shows that all investigated materials have the same distortions in the structure of the single phase - hydroxyapatite. It should be noted that the size of hydroxyapatite nanocrystals in the samples of the xenogenic material, according to the results of the calculations, is $11.1 \pm 0.6 \mathrm{~nm}$, which is less than in synthesized carbonatesubstituted calcium hydroxyapatite $33.0 \pm 1.5 \mathrm{~nm}$ or native bone $35.2 \pm 1.5 \mathrm{~nm}$. That fact refers to the diffraction patterns in increasing of diffraction peaks at the same position. Also, the intensity of some diffraction peaks decrease from sample to sample because of the different crystal growth orientation. This observation corresponds to the known data on the nanocrystalline nature of a bony skeleton [11].

It is known that in biological samples the ratio of $\mathrm{Ca} / \mathrm{P}$ are differ to the stoichiometric one -1.67 because of varies of elements in its structure and biochemical activity [25]. The high amount of calcium in the biological sample is due to the carbonate ion inclusion in the crystal structure of apatite. The data are in accordance with the results of [12, 23 25]. The biological samples (1 and 2) were distinguished from the synthetic HAP (sample 3) mainly based on the carbon content due to the presence of the organic component in biogenic materials. Moreover, this is the cause of a lower content of calcium and phosphorus in the samples 1 and 2 as compared with the synthesized sample 3 . The comparison of xenograft and jaw bone material by MA show that xenograft material has twice lower concentration of carbone and high amount of calcium and phosphorous. This fact can be referring to the pretreatment of the xenograft material and its high density.

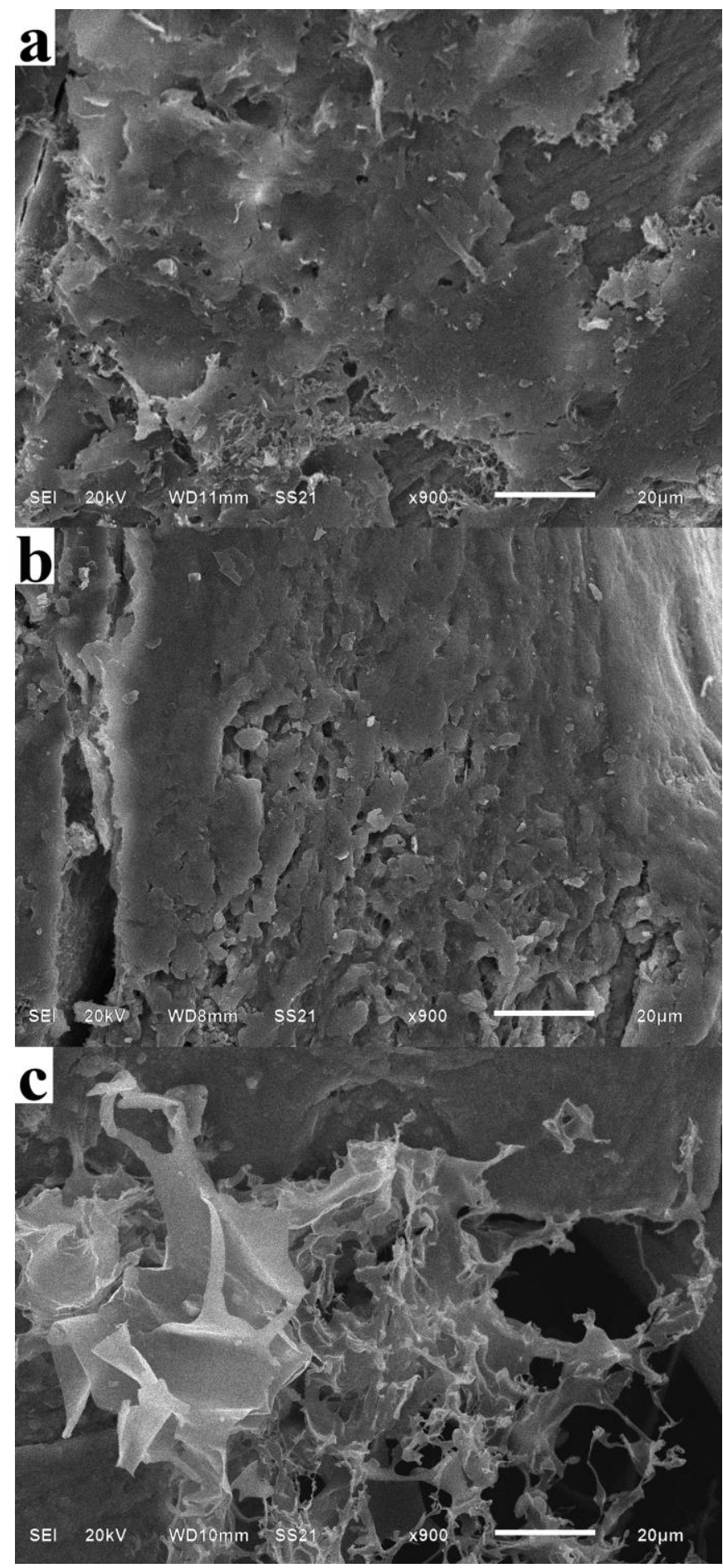

Figure 3. SEM microphotographs of morphology in the samples of bone tissue (left) and osteoplastic xenogenic materials (right) under x900 magnification.

The primary analysis of the experimental data demonstrated that all of the obtained spectra of the samples within each kind of material included the same set of vibration modes and were different in the intensities of certain vibration modes (Figure 1). Taking this in account, we averaged all spectra over the spectra data set of each kind of material. This allows us to avoid the elimination of random experimental errors. The analysis of IR- 
spectra were provided on the bases of source and knowing data of bone tissue vibration characteristics, oral cavity investigations and studies of synthetic bone graft materials [12, $20,26]$.

The obtained IR-spectroscopy results confirmed the data of the X-ray diffraction analysis that the main crystalline phase in the bone tissue and xenogenic material (curves 1 and 2 in Figure 1 ) is calcium hydroxyapatite which is characterized by stoichiometric formula $\mathrm{Ca}_{10}\left(\mathrm{PO}_{4}\right)_{6}\left(\mathrm{OH}_{2}\right)$. The fine structure of HAP is characterized by the presence of carbonate ion that is involved in the structure of hydroxyapatite in the positions of phosphorus-oxygen tetrahedron ( $\mathrm{PO}_{4}$ group) according to the known reference data $[3,25]$. Concerning with the organic compound in the investigated samples, according to the obtained data, amide groups of collagen protein (Amide I, II, III), which is present in the native bone tissue, were found in the composition of the synthetic materials [12]. It should be noted that in spite of the fact that the xenogenic material (sample 1) involved the described molecular groups in its composition (curve 1, Figure 1), but their content according to the experimental data in various xenograft samples proved to be a really specific one.

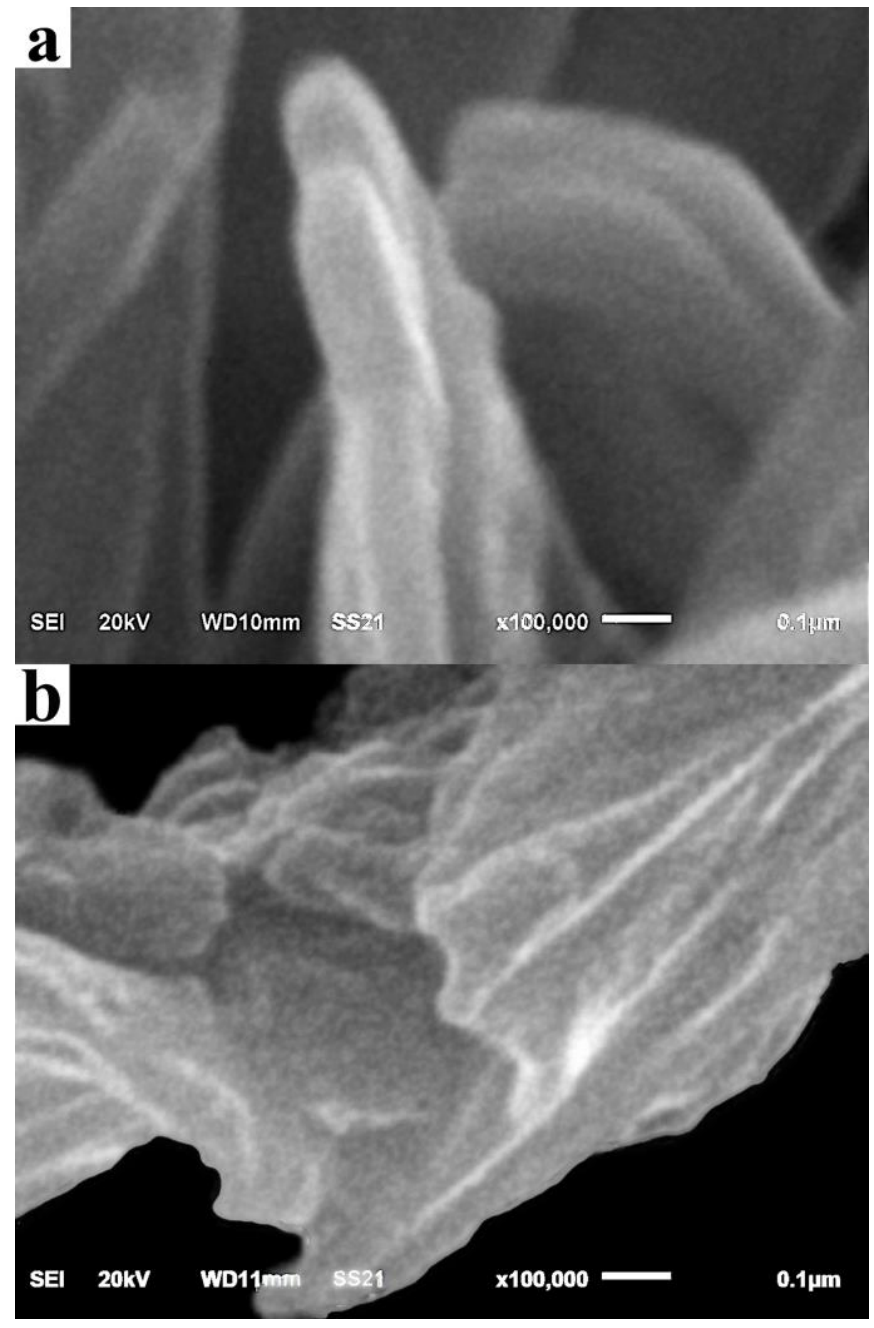

Figure 4. SEM microphotographs of morphology in the samples of bone tissue (left) and osteoplastic xenogenic materials (right) under x100000 magnification.
Based on the information concerning the features observed in the IR-spectra of organic compounds, the following was found. The redistribution of the intensities and asymmetry of vibrational modes observed in the IR-spectra corresponded to the changes occurring at the molecular level in the biological objects [12]. It means that besides collagen I in the xenograft composition (sample 1), some organic structures of another nature were observed that were absent in the native human bone tissue. This is probably due to the production treatment of xenograft. One should note that in the spectrum of sample 1 certain features (mode of vibrations) are observed in the ranges of $550-750$ and $1200-1800 \mathrm{~cm}^{-1}$ that are marked in Figure 1 with an asterisk. These modes in the IR-spectra correspond to the sulfated glycosaminoglycans [27] that are added to the xenogenic material in order to improve the reparative processes [16]. However, the comparison of the relative intensities of these vibration modes as collagen I with the data of the works on IR-spectra of xenogenic osteoplastic materials showing positive dynamics in restoration of dental tissue leads us to conclude that there is a disturbance of the material composition and the problem of concentration of the residual xenocollagen as well as that of sulfated glycosaminoglycans [27].

Figure 2 represents the images obtained with the use of optical microscope under $120 \times$ magnification from the mostly characteristic parts of the sample surface of the bony tissue (Figure 2a) and xenogenic blocks (Figure 2b). When considering the samples 1 and 2 (Figure 2), it is seen that in the sample of the bony tissue (Figure 2a) conjugated macropores are present with the sizes of more than $500 \mu \mathrm{m}$, while in the xenogenic samples (Figure 2b) size of the pores varies within the interval of pores from 120 to $250 \mu \mathrm{m}$ with the presence of inclusions and lower pores density per a surface unit. It is assumed that in order to attain sufficient bioresorption, a porous implant should be comprised of a system of interconnected open and mutually conjugated pores $[2,11]$. The distribution of the sizes for these pores should be within the limits of 50 to $500 \mu \mathrm{m}$, which is similar to the human bone tissue. Therefore, the absence of the large pores in the xenogenic material puts forward the issues concerning suitability of the implant obtained from the thigh bone of the animals in the way described above.

The investigations of the samples with the use of scanning electron microscopy demonstrated that these xenogenic materials possess the morphology and a system of conjugated pores similar to those of the human bone tissue. At the micrometer level the pores that are present in the xenograft coincide in their size with those in the native bone matrix $(3-10 \mu \mathrm{m})$ what is matches the previous investigations of xenograft materials [11]. At the same time the observed differences in the morphological organization of biogenic materials (Figures 3a, 3b) may be due to the organic component of the samples (collagen protein and its derivatives) and with the post-treatment of the xenogenic material that is revealed in its greater density and less development of its surface. The organic compound as it was shown by means of the IRspectroscopy technique is present both in the spongy bone tissue of a human and in the xenogenic material. However, it should be taken into account that the xenograft was subjected to a chemical and mechanical exposure at the stage of the material production as well as the addition of sulfated glycosaminoglycans. Thus, in this sample large corrugate-like structures are present on the surface of the basic material, probably, due to the organic component (Figure 3c). The presence of these structures means a disturbance 
of the treatment for the xenogenic material since the detected structures are not related with the basic matrix and they can provide side effects.

Under considerably higher magnification of x100000 (Figure 4) in the samples of the bone tissue (Figure 4a) and the xenogenic material (Figure $4 \mathrm{~b}$ ) the differences are observed as well. Collagenlike formations with a highly developed morphology are present in the bone at the sub-micrometer level while the morphology in the xenogenic material is characterized by the presence of considerably greater organic formations, which is probably the result of the treatment.

\section{Conclusion}

Based on the results of comparison of the structural, molecular and morphological properties of the studied samples, it is possible to conclude that the samples of the osteoplastic materials do not completely correspond to the spongy human bone tissue, which imposes certain constraints on their practical applications. The porous structure found at the macrolevel of the xenogenic material as well as a higher density along with smaller nanocrystals compared to the bone tissue of the lower human jaw identifies possible risks associated with using the biomimetic composite for recreating the defects of the lower human jaw. Comparison of the structure, phase and molecular composition as well as the morphology of the samples of native porous bone tissue and xenogenic materials allowed us to identify the principal differences between the two materials as well as to design the requirements and guidelines for manufacturers on extra processing of a xenogenic material for eliminating the factors affecting the quality of implantation and resorption of a biomimetic composite: macroporosity, crystallinity and molecular composition.

\section{Limitations}

The only limitation in the study is the size of the selection of the synthesized and investigated samples. We do not think it is significant and has any considerable impact on the results of the study due to the homogeneity of the samples synthesized in a single cycle as well as selected for the analysis of the materials that do not affect the testing methods.

\section{Funding}

This study was supported by the grant of Russian Science Foundation, grant number 16-15-00003.

\section{Conflict of Interests}

The authors declare no conflict of interests.

\section{Ethical approval}

All the procedures performed in studies involving human participants were in accordance with the ethical standards of the institutional research committee and with the 1964 Helsinki declaration and its later amendments or comparable ethical standards.

\section{References}

1. Abueva CDG, Jang DW, Padalhin A, Lee BT. Phosphonate-chitosan functionalization of a multi-channel hydroxyapatite scaffold for interfacial implant-bone tissue integration. J Mater Chem B 2017; 5(6): 1293-1301. http://doi.org/10.1039/C6TB03228A.

2. Jang SJ, Kim SE, Han TS, Son JS, Kang SS, Choi SH. Bone Regeneration of Hydroxyapatite with Granular Form or Porous Scaffold in Canine Alveolar Sockets. In Vivo 2017; 31(3): 335-341. http://doi.org/10.21873/invivo.11064.

3. Seredin PV, Goloshchapov DL, Prutskij T, Ippolitov YA. Fabrication and characterisation of composites materials similar optically and in composition to native dental tissues. Results Phys 2017; 7: 1086-1094. http://doi.org/10.1016/j.rinp.2017.02.025.

4. Finoli A, Schmelzer E, Over P, Nettleship I, Gerlach JC. Open-Porous Hydroxyapatite Scaffolds for Three-Dimensional Culture of Human Adult Liver Cells. Biomed Res Int 2016; 2016: 6040146. http://doi.org/10.1155/2016/6040146.

5. Berberi A, Samarani A, Nader N, Noujeim Z, Dagher M, Kanj W, et al. Physicochemical characteristics of bone substitutes used in oral surgery in comparison to autogenous bone. Biomed Res Int 2014; 2014: 320790. http://doi.org/10.1155/2014/320790

6. Mahyudin F, Utomo DN, Suroto H, Martanto TW, Edward M, Gaol IL. Comparative Effectiveness of Bone Grafting Using Xenograft FreezeDried Cortical Bovine, Allograft Freeze-Dried Cortical New Zealand White Rabbit, Xenograft Hydroxyapatite Bovine, and Xenograft Demineralized Bone Matrix Bovine in Bone Defect of Femoral Diaphysis of White Rabbit: Experimental Study In Vivo. Int J Biomater 2017; 2017: 7571523. http://doi.org/10.1155/2017/7571523.

7. Chaoliang LV, Song Y. Novel biodegradable MAACP/n-HA (multi-aminoacid copolymer/nano-hydroxyapatite) composite artificial lamina following spinal surgery for Lamina reconstruction. Bone Jt J 2013; 95B $\quad$ (SUPP 14$): ~ 80$ https://online.boneandjoint.org.uk/doi/abs/10.1302/1358992X.95BSUPP 14.SAOA2012-080.

8. Zhou C, Ye X, Fan Y, Ma L, Tan Y, Qing F, et al. Biomimetic fabrication of a three-level hierarchical calcium phosphate/collagen/hydroxyapatite scaffold for bone tissue engineering. Biofabrication 2014; 6(3): 035013. http://doi.org/10.1088/1758-5082/6/3/035013.

9. Brasinika D, Tsigkou O, Tsetsekou A, Missirlis YF. Bioinspired synthesis of hydroxyapatite nanocrystals in the presence of collagen and Iarginine: Candidates for bone regeneration. J Biomed Mater Res B Appl Biomater 2015; 04(3): 458-69. http://doi.org/10.1002/jbm.b.33413.

10. Seredin PV, Goloshchapov DL, Kashkarov VM, Lukin AN, Gushchin MS, Ippolitov YA, et al. Structural and Spectroscopic Investigation of Biomimetic Composites-Promising Agents for the Remineralization of Native Dental Tissue. J Synch Investig 2018; 12(3): 442-451. http://doi.org/10.1134/S1027451018020131.

11. Ramírez Fernández MP, Gehrke SA, Pérez Albacete Martinez C, Calvo Guirado JL, de Aza PN. SEM-EDX Study of the Degradation Process of Two Xenograft Materials Used in Sinus Lift Procedures. Materials (Basel) 2017; 10(5): E542. http://doi.org/10.3390/ma10050542.

12. Figueiredo MM, Gamelas JAF, Martins AG. Characterization of bone and bone-based graft materials using ftir spectroscopy. In: Infrared Spectroscopy - Life and Biomedical Sciences. InTech, 2012: 315-338. http://doi.org/10.5772/36379.

13. Cao ZD, Jiang DM, Yan L, Wu J. Biosafety of the Novel Vancomycinloaded Bone-like Hydroxyapatite/Poly-amino Acid Bony Scaffold. Chin Med J (Engl). 2016; 129(2): 194-199. http://doi.org/10.4103/03666999.173489.

14. Kim JW, Shin KH, Koh YH, Hah MJ, Moon J, Kim HE. Production of Poly( $\varepsilon$-Caprolactone)/Hydroxyapatite Composite Scaffolds with a Tailored Macro/Micro-Porous Structure, High Mechanical Properties, and Excellent Bioactivity. Materials (Basel) 2017; 10(10): E1123. http://doi.org/10.3390/ma10101123. 
15. Wong ML, Griffiths LG. Immunogenicity in xenogeneic scaffold generation: Antigen removal versus decellularization. Acta Biomater 2014; 10(5): 1806-1816. http://doi.org/10.1016/j.actbio.2014.01.028.

16. Mikhaĭlovskiĭ AA, Kulakov AA, Korolev VM, Vinnichenko OI. Clinical and radiological study on tissue regeneration after alveolar bone augmentation with various osteoplastic materials and membranes. Stomatologiia (Mosk) 2014; 93(4): 37-40. Russian. https://www.ncbi.nlm.nih.gov/pubmed/25377579.

17. Goloshchapov DL, Kashkarov VM, Rumyantseva NA, Seredin PV, Lenshin AS, Agapov BL, et al. Synthesis of nanocrystalline hydroxyapatite by precipitation using hen's eggshell. Ceram Int 2013; 39(4): 4539-4549. http://doi.org/10.1016/i.ceramint.2012.11.050.

18. Seredin P, Kashkarov V, Lukin A, Ippolitov $Y$, Julian R, Doyle S. Local study of fissure caries by Fourier transform infrared microscopy and Xray diffraction using synchrotron radiation. J Synchrotron Radiat 2013; 20(Pt 5): 705-710. http://doi.org/10.1107/S0909049513019444.

19. Liu Y, Yao X, Liu YW, Wang Y. A Fourier Transform Infrared Spectroscopy Analysis of Carious Dentin from Transparent Zone to Normal Zone. Caries Res 2014; 48(4): 320-329. http://doi.org/10.1159/000356868.

20. Seredin PV, Goloshchapov DL, Ippolitov YA, Kalivradzhiyan ES. Does dentifrice provide the necessary saturation of ions in oral fluids to favour remineralisation? Russ Open Med J 2018; 7(1): e0106. http://doi.org/10.15275/rusomj.2018.0106.

21. Seredin P, Goloshchapov D, Ippolitov Y, Vongsvivut P. Pathologyspecific molecular profiles of saliva in patients with multiple dental caries-potential application for predictive, preventive and personalised medical services. EPMA J 2018; 9(2): 195-203. http://doi.org/10.1007/s13167-018-0135-9.

22. Seredin P, Goloshchapov D, Kashkarov V, Ippolitov Y, Bambery K. The investigations of changes in mineral-organic and carbon-phosphate ratios in the mixed saliva by synchrotron infrared spectroscopy. Results Phys 2016; 6: 315-321. http://doi.org/10.1016/i.rinp.2016.06.005.

23. Buddhachat $K$, Klinhom $S$, Siengdee $P$, Brown JL, Nomsiri R, Kaewmong $P$, et al. Elemental Analysis of Bone, Teeth, Horn and Antler in Different Animal Species Using Non-Invasive Handheld X-Ray Fluorescence. PLOS One 2016; 11(5): e0155458. http://doi.org/10.1371/journal.pone.0155458.

24. Seredin PV, Goloshchapov DL, Kashkarov VM, Ippolitov YA, Prutskij T. Emission properties of biomimetic composites for dentistry. Results Phys 2016; 6: 447-448. http://doi.org/10.1016/j.rinp.2016.08.003.

25. Piga G, Gonçalves D, Thompson TJU, Brunetti A, Malgosa A, Enzo S. Understanding the Crystallinity Indices Behavior of Burned Bones and Teeth by ATR-IR and XRD in the Presence of Bioapatite Mixed with Other Phosphate and Carbonate Phases. Int J Spectrosc 2016; 2016 : 4810149. http://doi.org/10.1155/2016/4810149.

26. Seredin P, Goloshchapov D, Prutskij T, Ippolitov Y. Phase Transformations in a Human Tooth Tissue at the Initial Stage of Caries. PLoS One 2015; 10(4): e0124008. http://doi.org/10.1371/journal.pone.0124008.

27. Mainreck N, Brézillon S, Sockalingum GD, Maquart FX, Manfait $M$, Wegrowski Y. Rapid characterization of glycosaminoglycans using a combined approach by infrared and Raman microspectroscopies. J Pharm Sci 2011; 100(2): 441-450. http://doi.org/10.1002/jps.22288.

\section{Authors:}

Pavel V. Seredin - PhD, Associate Professor, Department of Solid State Physics and Nanostructures, Voronezh State University, Voronezh, Russia. http://orcid.org/0000-0002-6724-0063.

Dmitry L. Goloshchapov - PhD, Scientific Researcher, Department of Solid State Physics and Nanostructures, Voronezh State University, Voronezh, Russia. http://orcid.org/0000-0002-1400-2870.

Maksim S. Gushchin - Postgraduate Student, Department of Solid State Physics and Nanostructures, Voronezh State University, Voronezh, Russia. http://orcid.org/0000-0002-3762-7566.
Yuri A. Ippolitov - PhD, Head of Department of pediatric dentistry with orthodontia, Voronezh State Medical University, Voronezh, Russia. http://orcid.org/0000-0001-9922-137X.

Vladimir M. Kashkarov - Associate Professor, Department of Solid State Physics and Nanostructures, Voronezh State University, Voronezh, Russia. http://orcid.org/0000-0001-9460-9244.

Dmitry E. Suetenkov - MD, PhD, Head of Department Children's Stomatology and Orthodontics, Saratov State Medical University, Saratov, Russia. http://orcid.org/0000-0003-3967-2624 